\title{
PERFORMANCE EVALUATION OF LOS MICROWAVE RADIOS USING A CHANNEL SIMULATOR
}

J. A. Hoffmeyer, L. E. Pratt, and T. J. Riley

\author{
U.S. Department of Commerce \\ National Telecommunications and Information Administration \\ Institute for Telecommunication Sciences \\ Boulder, Co 80303-3328
}

\section{ABSTRACT}

This paper describes a line-of-sight (LOS) channel simulator that can be used for the laboratory evaluation of microwave radios. The simulator has a unique design, utilizes state-ofthe-art microwave circuitry, and is completely under computer control. The hardware and software design concepts incorporated in the simulator are described. Results from tests conducted on a military microwave radio are presented. The results show the sensitivity of an unprotected radio to small changes in amplitude distortion of the received signal. Static m-curve signatures are also presented. The need to simulate the dynamics of frequency selective fading is described. Small changes to the simulator which will provide such dynamic operation are planned.

\section{INTRODUCTION}

Many authors have reported that multipath fading, i.e., frequency-selective or dispersive fading, is the dominant reason for propagationcaused outages in microwave digital radio systems (refs. 1-8). Greenfield (ref. 8) stated that dispersive fading was virtually the sole cause of outage on a long, $6-\mathrm{GHz}$ path in the Western United States. Frequency-selective fading has a much greater effect on digital radio performance than it does on analog radio performance (ref. 1). In analog radio transmission, the major source of propagation-related outage is flat fading rather than frequency-selective fading. For analog systems, frequency-selective fading does cause intermodulation distortion, but this effect is secondary to flat fading. For digital radios, the effect of frequency-selective fading is much more severe. Unlike analog systems, digital radios are relatively insensitive to flat fading and are primarily affected by dispersive multipath fading (ref. 6). This will be demonstrated later in this paper.

In the last decade, numerous techniques have been devised to mitigate the effects of frequencyselective fading on digital microwave radios. These techniques include: space diversity, frequency diversity, angle diversity, polarization diversity, adaptive equalizers, and more robust modulation schemes. Both vertical and horizontal (ref. 9) separation of space diversity antennas have been utilized. Several types of adaptive equalizers have been developed, including both slope (frequency domain) and transversal filter (time domain) equalizers. Many of these techniques are currently incorporated in commercially available digital radios.
The task of evaluating the relative effectiveness of the above techniques is a particularly difficult one. In general, radio performance can be estimated either theoretically, through field measurements, through the use of channel simulators, or through a selected combination of these three. Some of the advantages of channel simulators' use are (ref. 10): cost, repeatability, accuracy, complete testing over a full raree of channel conditions, and testbed availability. When considering a competitive procurement of of $f$-the-shelf digital radios for use in military communications systems, the first two advartages are particularly strong arguments for the use of channel simulation. The comparative performane evaluation of several radios requires that the testing be conducted under identical test conditions. This can be done most economically in the liboratory using a channel simulator.

\section{CHANNE: MODELS}

Several different mathematical models have been proposed to represent frequency-selective fading on LOS microwave paths (refs. 11-17). A variety of channel simulators based on these models have been developed (refs. 16 and 18-21, for example). Most of the models are multipath transfer models based on the work of Rummler (ref. 13) and on the earlier work of Emshwiller (ref. 11) and Jakes (ref. 12). A power series model has also been postulated by Greenstein and Czekaj (ref. 14). Both the Rummler and Greenstein models have been shown to represent fading accurately on a 26.4-mile $(42.3 \cdots \mathrm{km})$ path in Georgia. The most widely accepted model appears to be that of Rummler, although the notation used by others and their interpretation have differed somewhat.

Using the notation of Matsuura (ref. 16), the model is expressed as:

$$
H(\omega)=a\left(1+b e^{j(\omega \tau+\phi)}\right) \text {. }
$$
In equation (1), a represents flat fading, b represents the amplitude of the indirect path relative to the direct path, $\tau$ represents the relative delay between the two paths, $w$ represents the carrier frequency in the band of interest, and $\phi$ is an arbitrary phase. Unlike Rummler, we do not restrict $\tau$ to a fixed value of $6.3 \mathrm{~ns}$. As will be demonstrated, error performance of a digital radio is affected by changes in $\tau$. We define the following quantities:

$$
\begin{aligned}
& A=20 \log _{10}(a), \\
& B^{\prime}=20 \log _{10}(b), \text { and } \\
& B=20 \log (1-b) .
\end{aligned}
$$




\section{DESCRIPTION OF SIMULATOR}

At the start of this project there were several objectives for the simulator: (1) the channel simulator must be implemented at $\mathrm{rf}$, (2) the control of the simulator must be automated, (3) the simulator should permit variation in the delay parameter, $\tau$, and (4) the simulator should be made dynamic if possible. A dynamic simulator is one in which the simulator parameters can be changed on a continuous basis as opposed to a static simulator in which the parameters are changed in discrete steps. The first three objectives were totally met. The state-of-the-art microwave component technology did not permit meeting both the first and the last objectives simultaneously. Because of the importance placed on testing a complete radio, including all its $r f$ components, we chose an implementation at $\mathrm{rf}$ even though this decision made it impossible, at that time, to meet the dynamic objective. However, new improved phase shifters have now become available. They will permit this last objective to be met. Consequently, a modification to the simulator is planned, as will be discussed in the last section of this paper.

Most of the LOS microwave channel simulators have been developed are intermediate frequency (IF) implementations of Rummler's model. Some have been implemented at $\mathrm{rf}$ (refs. 19-21). The simulator reported in Reference 19 is a partially dynamic simulator implemented at $\mathrm{rf}$ that has a fixed value of $\tau=6.3 \mathrm{~ns}$.

Figure 1 is a functional block diagram of the simulator which we have constructed. The relative delay, $\tau$, between the direct and indirect paths is provided by switching in various lengths of semirigid coax lines in the switched delay sections. Five different lengths of cable can be switched into the circuit, either individually or in any combination. Any value of delay from 0 to 31 ns in 1-ns increments can be achieved. Variation of $\tau$ causes changes in both the location and shape of the notch in the spectrum created by the phasor addition of the direct and indirect path signals. The programmable phase shifter is used to move the notch across the spectrum. Thus, we can control both notch shape (through the parameter $\tau$ ) and the notch location (through a combination of $\tau$ and $\phi)$. The programmable attenuator in the indirect path represents the parameter $b$. The depth of the notch is controlled through this parameter. Both nonminimum phase and minimum phase conditions can be simulated by changing the sign of $B^{\prime}$. The other programmable attenuator represents the parameter a; i. e., the flat fading parameter. The manual attenuator at the input to the simulator reduces the signal level of the transmitter under test to levels that are compatible with the receiver section of the radio being tested.

One concern throughout this project has been to design the system such that changes in relative delay between the two paths would not change the relative signal level between the two paths and vice versa. That is, relative phase and relative amplitude of the two paths must be independently controlled. Care was taken in the design and implementation of the system to ensure that this was accomplished. For this reason, a signal leveler is needed in the indirect path so that the signal level does not change when additional delay is placed in the indirect path by switching in the additional delay sections.

The purpose of the attenuator and line stretcher in the direct path is to make the delay and the attenuation of the indirect and direct paths equal when there is zero relative delay in the indirect path.

All of the parameters shown in Figure 1 ( $a, b$, $\phi$ and $\tau$ ) can be controlled by the computer. The simulator can be used at any frequency in the 4-12 $\mathrm{GHz}$ band.

Figure 2 is a picture of the simulator hardware. It occupies 5.25 inches $(13.3 \mathrm{~cm})$ of vertical space in a standard 19-inch $(48.3-\mathrm{cm})$ rack.

\section{TEST RESULTS}

The channel simulator has been used to evaluate the performance of the DRAMA (Digital Radio and Multiplexer Acquisition) radio. This radio has been installed in portions of the Defense Communications System (DCS). Reference 22 describes the DRAMA radio in some detail. The version of the radio tested combines two mission bit streams, each at $12.928 \mathrm{Mb} / \mathrm{s}$, and utilizes quadrature partial response modulation. The radio does not have an adaptive equalizer, but it does have both space and frequency dual diversity versions. The tests reported here, however, were run only on a single channel, i.e., no diversity. A single mission bit stream of $12.928 \mathrm{Mb} / \mathrm{s}$ was tested. The test configuration is depicted in Figure 3. The purpose of the amplifier between the simulator and the spectrum analyzer is for ease of viewing the simulator output signal, including the notch in the spectrum. The amplifier does not create additional distortion of the signal over the frequencies of interest.

Figure 4 depicts the amplified output of the channel simulator as seen on the spectrum analyzer. The difference between the two traces is the difference in the setting of the value for $\phi$. The figure demonstrates the deep notches that can be obtained with the simulator. The values of $\phi$ given in the figure caption are the phase shifts provided by the phase shifter and do not give the total phase difference between the direct and indirect signal paths. Other components in the two paths also impart some amount of phase shift.

Figure 5 demonstrates the effect of small changes in values of phase on the notch location. The phase shifter employed in the simulator has 8 bits of digital control. This gives 256 discrete steps of about $1.4^{\circ}$ each. The expected frequency shift for the notch location may be found from:

$$
\mathrm{f}_{\mathrm{S}}=\left(\Delta \phi / 360^{\circ}\right) \cdot(1 / \tau)
$$

For $\Delta \phi=14.1^{\circ}$ and $\tau=10 \mathrm{~ns}, \mathrm{f}_{\mathrm{S}}$ is calculated to be $3.92 \mathrm{MHz}$. From an examination of Figure 5, one can roughly verify that the actual frequency shift obtained was that predicted. This verifies the operation of the phase shifter at this rf frequency. The phase shifter utilized in the simulator operates in the range of $4-12 \mathrm{GHz}$.

Figure 6 illustrates the sensitivity of the DRAMA radio to small changes in the $\phi$ parameter. Although the difference in the spectrum for the two traces does not appear significant, the effect on an unprotected radio is dramatic. The observed bit 
error ratio (BER) corresponding to the upper trace was on the order of $1 \times 10^{-6}$, while that of the lower trace was on the order of $1 \times 10^{-4}$. Figure 7 illustrates the sensitivity of the DRAMA radio to changes in $B^{\prime}$ (the relative signal strength parameter), but not to A (the flat fade parameter). For all three traces in the figure, $\phi$ remains unchanged at a value that would cause a notch in the center of the radio passband if the $B^{\prime}$ parameter were increased. The difference between the top trace and the bottom trace is that an additional $10 \mathrm{~dB}$ of flat fading has been inserted by changing the A parameter. No errors occurred in the DRAMA radio for either case. However, a small change of $1.2 \mathrm{~dB}$ in the $\mathrm{B}^{\prime}$ parameter (see center trace in Figure 7) caused the $B E R$ performance of the radio to drop to $1 \times 10^{-4}$. One can discern a slight amount of amplitude distortion in the middle trace. The figure demonstrates the susceptibility of digital radios to amplitude distortion. The switching algorithm used in the DRAMA radio is based on received signal level ( $r s l)$. From an examination of Figure 7 , one could conclude that because of the switching algorithm in the radio, the space diversity capability of the radio will not improve performance in a frequency selective fading environment.

Small changes in $B^{\prime}$ dramatically alter the spectral output of the simulator as illustrated in Figure 8. Note the change in output for $B^{\prime}=-3.0 \mathrm{~dB}$ (top trace) and $B^{\prime}=0.0$ (bottom trace). The performance of the radio was as follows: zero errors for the top trace, $B E R=1 \mathrm{x}$ $10^{-7}$ for the second trace (due to a small amount of amplitude distortion), and loss of synchronization for the bottom three traces. Thus a change of only $3 \mathrm{~dB}$ caused a change from error-free performance to a loss of synchronization.

Figure 9 illustrates the extent to which the rsl can drop before errors occur. This is the flat fading threshold for this particular radio. With the particular values of $\tau$ and $\phi$ used, the notch created by the simulator is well outside the passband of the radio. Therefore, there is no distortion from simulated frequency-selective fading.

The figures described above serve to illustrate graphically the following points: 1) the simulator is a useful device for simulating frequency-selective fading, 2) unprotected digital radios are extremely sensitive to small distortions in the received signal, and 3) changes to the diversity switching algorithm used in the DRAMA radio and the use of adaptive equalization should be considered. The data presented in these figures verify the contention of Barnett (ref. 23) that distortion of as little as $0.2 \mathrm{~dB} / \mathrm{MHz}$ can cause unacceptable performance for an unprotected digital radio.

Figures 10 and 11 are static "m-curves" for the unprotected (i.e., no equalizer and no diversity) DRAMA radio. The curves in Figure 11 are for the nonminimum fading case which results from positive values of the $B^{\prime}$ parameter. This causes the indirect-path signal to be stronger than the direct-path signal. This situation can occur about 50 percent of the time for deep fades (refs. 6 and 24). The figures illustrate the effect of changes in $\tau$ on digital radio performance.

\section{FUTURE WORK}

The above test results have demonstrated the capability of the channel simulator for testing LOS microwave radios. A second simulator channel, which is necessary for testing diversity configurations of the radio, is being constructed. The simulator has the capability for developing static equipment signatures which can be utilized to predict outages for a given link using procedures such as those developed by Emshwiller ( $r \in f .11$ ). However, the static signatures are not adequate predictors of performance unless the entire radio system, including equalizers and diversity switching/combining subsystems, can respond as fast as the channel parameters change. We therefore plan to modify the simulator for dynamic operation.

The key to the development of a dynamic capability is the acquisition of a phase shifter that operates over the $4-12 \mathrm{GHz}$ range and that can be controlled by analog voltage. Such a device recently has become available.

A critical aspect of all channel simulators is that they be based on a model that accurately represents the main traits of the channel. The dynamic aspect of microwave frequency-selective fading is not well understood. Leclert and Vandamme (ref. 4) question the classical assumption that the channel is slowly varying in comparison to the symbol rate. Table I provides some statistics on the rate of change of amplitude and notch frequency. The recent work of Kolton (ref. 24) will add greatly to this body of knowledge. The corresponding model of the dynamic behavior of multipath fading will be implemented in the simulator. This will result in a more realistic performance evaluation of digital radios than that obtainable from static m-curves.

Table I. Dynamic Multipath Characterization

\begin{tabular}{|c|c|c|}
\hline Source & $\begin{array}{l}\text { Rate of Amplitude } \\
\text { Change }(\mathrm{dB} / \mathrm{s})\end{array}$ & $\begin{array}{l}\text { Rate of Notch } \\
\text { Frequency Change } \\
(\mathrm{MHz} / \mathrm{s})\end{array}$ \\
\hline $\begin{array}{l}\text { Leclert and } \\
\text { Vandamme }\end{array}$ & $\begin{array}{l}<100 \mathrm{~dB} / \mathrm{s} \text { in } 99 \% \\
\text { of cases }\end{array}$ & $\begin{array}{l}<600 \mathrm{MHz} / \mathrm{s} \text { in } \\
99 \% \text { of cases }\end{array}$ \\
\hline
\end{tabular}

(ref. 4)

Fenderson,

Meyers, and

Skinner (ref.6)

Siller

(ref. 26)

Gardina and

Vigants

(ref. 25)
$<20 \mathrm{MHz} / \mathrm{s}$ most of the time

$50 \mathrm{MHz} / \mathrm{s}$

$100 \mathrm{~dB} / \mathrm{s}$

$<10 \mathrm{~dB} / \mathrm{s}$ for $11 \%$ of fading time

<15 MHz/s for $99 \%$ of fading time 


\section{ACKNOWLEDGMENTS}

The authors gratefully acknowledge support given by the U.S. Army. Specifically, Mr. F. Dwulet and LTC C. Medvitz provided program management and funding support. Mr. S. Matsuura and $\mathrm{Mr}$. D. Laida provided technical suggestions during the course of this project. Mr. R. Linfield of ITS also provided encouragement and suggestions.

The views, opinions, and findings contained in this report are those of the authors and should not be construed as an official Department of the Army position, policy or decision, unless so designated by other official documentation. Clearance of this paper does not construe an endorsement by the Department of the Army of the products or services discussed herein.

\section{REFERENCES}

1. D. Smith, Digital Transmission Systems, Van Nostrand Reinhold Co., New York, 1985.

2. A. J. Giger and W. T. Barnett, "Effects of Multipath Propagation on Digital Radio," IEEE Trans. on Comm., Vol. COM-29, No. 9, Sept. 1981, pp. 1345-1352.

3. Y. Serizawa and S. Takeshita, "A Simplified Method for Prediction of Multipath Fading Outage of Digital Radio," IEEE Trans. on Comm., Vol. COM-31, No. 8, August 1983, pp. 1017-1021.

4. A. Leclert and P. Vandamme, "Decision Feedback Equalization of Dispersive Radio Channels," IEEE Trans. on Comm., Vol. COM-33, No. 7, July 1985 , pp. 676-684.

5. G. J. Foschini and J. Salz, "Digital Communications Over Fading Channels," IEEE 1983 Intl. Conf. on Comm., Boston, MA, Paper No. C8.1.

6. G. L. Fenderson, M. H. Meyers, and M. A. Skinner, "Recent Advances in Multipath Propasation Countermeasures for High-Capacity Digital Radio Systems," IEEE 1985 Intl. Conf. on Comm., Chicago, IL, Paper No. 39.2 .

7. J. A. Schiavone, "Meteorological Effects on Diurnal and Seasonal Fading Variations," IEEE 1983 Intl. Conf. on Comm., Boston, MA, Paper No. C2.2.

8. P. E. Greenfield, "Digital Radio Performance on a Long, Highly Dispersive Fading Path," IEEE 1984 Intl. Conf. on Comm., Amsterdam, Holland, pp. $1451-1454$.

9. M. F. Gardina and S. H. Lin, "Measured Performance of Horizontal Space Diversity on a Microwave Radio Path," IEEE 1985 Global Telecomm. Conf., New Orleans, LA, Paper No. 36.6.

10. J. A. Hoffmeyer and W. J. Hartman, "LOS Microwave Channel Simulation - A Survey of Models, Realizations and New Concepts," NATO AGARD Conf. Proc. No. 363, Propagation Influences on Digital Transmission Systems: Problems and Solutions, Athens, Greece, June 1984.
11. M. Emshwiller, "Characterization of the Performance of PSK Digital Radio Transmission in the Presence of Multipath Fading," IEEE 1978 Intl. Conf. on Comm., Toronto, Canada, Paper No. 47.3.

12. W. C. Jakes, Jr., "An Approximate Method to Estimate an Upper Bound on the Effect of Multipath Delay Distortion on Digital Transmission," IEEE Trans. on Comm., Vol. COM-27, No. 1, Jan. 1979, pp. 76-81.

13. W. D. Rummler, "A New Selective Fading Model: Application to Propagation Data," BSTJ, Vol. 58, No. 5, May-June, 1979, pp. 1037-1071.

14. L. J. Greenstein and B. A. Czekaj, "A Polynomial Model for Multipath Fading Channel Responses," BSTJ, Vol. 59, No. 7, Sept. 1980, pp. $1197-1225$.

15. 0. Sasaki and T. Akiyama, "Multipath Delay Characteristics on Line-of-Sight Microwave Radio System," IEEE Trans. On Comm., Vol. COM-27, No. 12, Dec. 1979, pp.1876-1886.

16. S. T. Matsuura, "Estimated Performance of a QPR Digital Microwave Radio in the Presence of Frequency Selective Fading," IEEE 1982 Intl. Conf. on Comm., Philadelphia, PA, Paper No.7B.2.

17. M. Meyers, "Multipath Fading Characteristics of Broadband Radio Channels," IEEE 1984 Global Telecomm. Conf., Atlanta, GA, Paper No. 45.1.

18. A. J. Rustako, C. B. Woodworth, R. S. Roman, and H. H. Hoffman, "A Laboratory Simulation Facility for Multipath Fading Microwave Radio Channels," AT\&T Tech. J., Vol. 64, No. 10, Dec. 1985, pp. 2281-2317.

19. R. Valentin, K. Metzger, and R. Schneckenburger, "Performance Analysis of Diversity and Equalization Techniques Using a Selective Fading Simulator and Computer Modeling," IEEE 1985 Intl. Conf. on Comm., Chicago, IL, Paper No. 39.3.

20. H. J. Bessai and W. Lorek, "Influence of Multipath Fading on the Multiplexing Factor of 140 Mbit/s 16-QAM Radio-relay Systems," IEEE 1984 Global Telecomm. Conf., Atlanta, GA, Paper No. 45.4 .

21. J. Bursztejn, "Influence de la Propagation Dans Les Faisceaux Hertziens Numeriques," NATO AGARD Conf. Proc. No. 363, Propagation Influences on Digital Transmission Systems: Problems and Solutions, Athens, Greece, June 1984.

22. C. M. Thomas, J. E. Alexander, and E. W. Rahneberg," A New Generation of Digital Microwave Radios for U.S. Military Telephone Networks," IEEE Trans. on Comm., Vol. COM-27, No. 12, Dec. 1979, pp. 1916-1928. 
23. W. T. Barnett, "Multipath Fading Effects on Digital Radio," IEEE Trans. on Comm., Vol. COM-27, No. 12, Dec. 1979, pp. 1842-1848.

24. E. Kolton, "Results and Analysis of Static and Dynamic Multipath In a Severe Atmospheric Environment, NTIA Report in publication, Institute for Telecommunication Sciences, Boulder, CO 803033328.
25. M. F. Gardina and A. Vigants, "Measured Multipath Dispersion of Amplitude and Delay at 6 $\mathrm{GHz}$ in a $30 \mathrm{MHz}$ Bandwidth," IEEE 1984 Intl. Conf. on Comm., Amsterdam, Holland, pp. 1433-1436.

26. C. A. Siller, "Multipath Propagation," IEEE Comm. Mag., Vol. 22, No. 2, Feb. 1984, pp. 6-15.

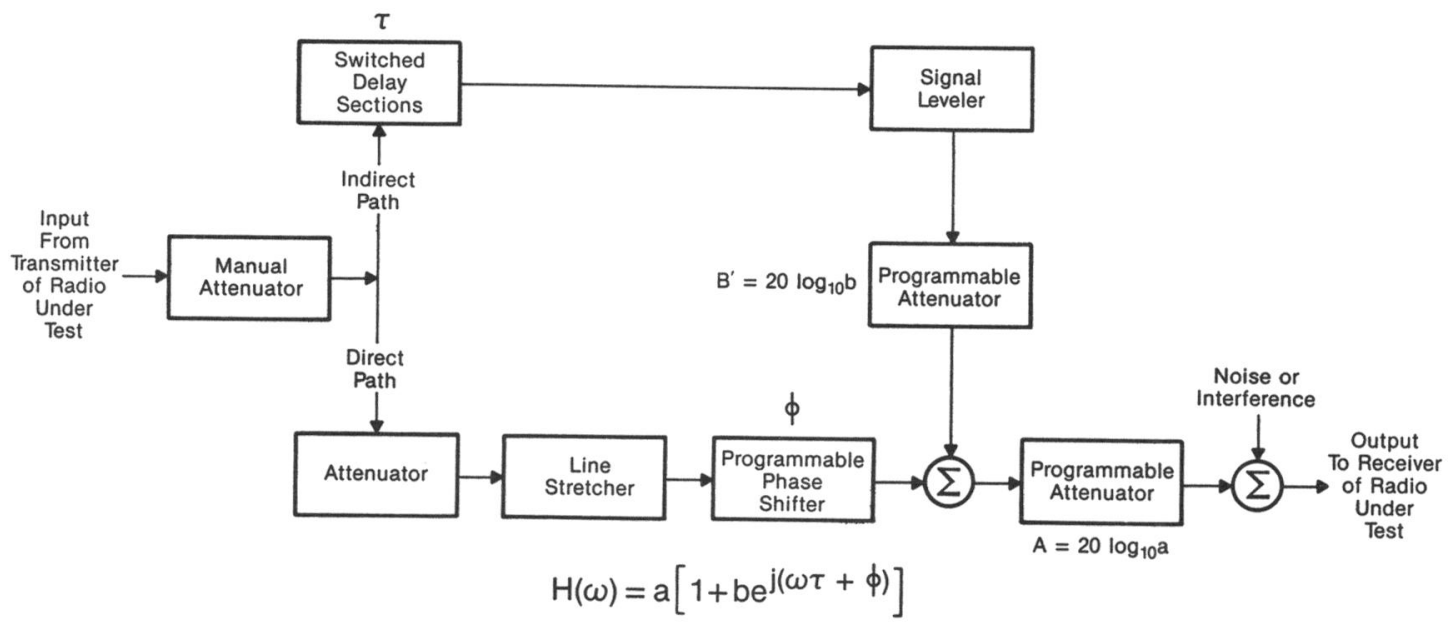

Figure 1. Simulator functional block diagram.

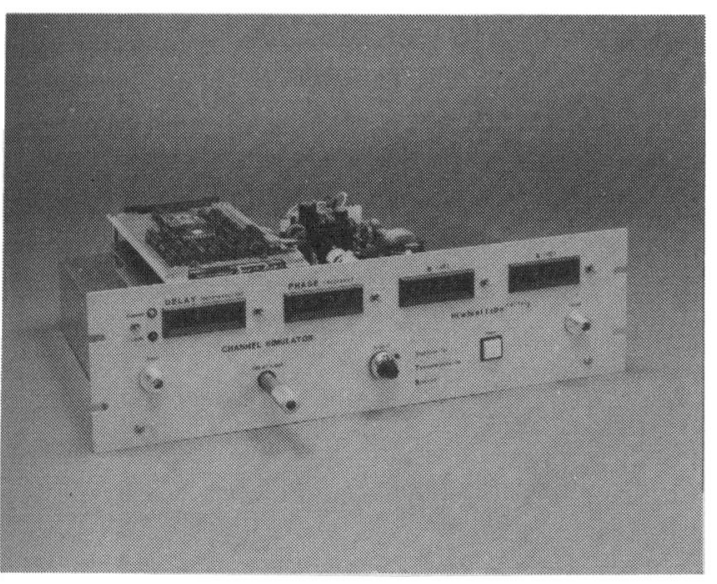

Figure 2. Simulator hardware.

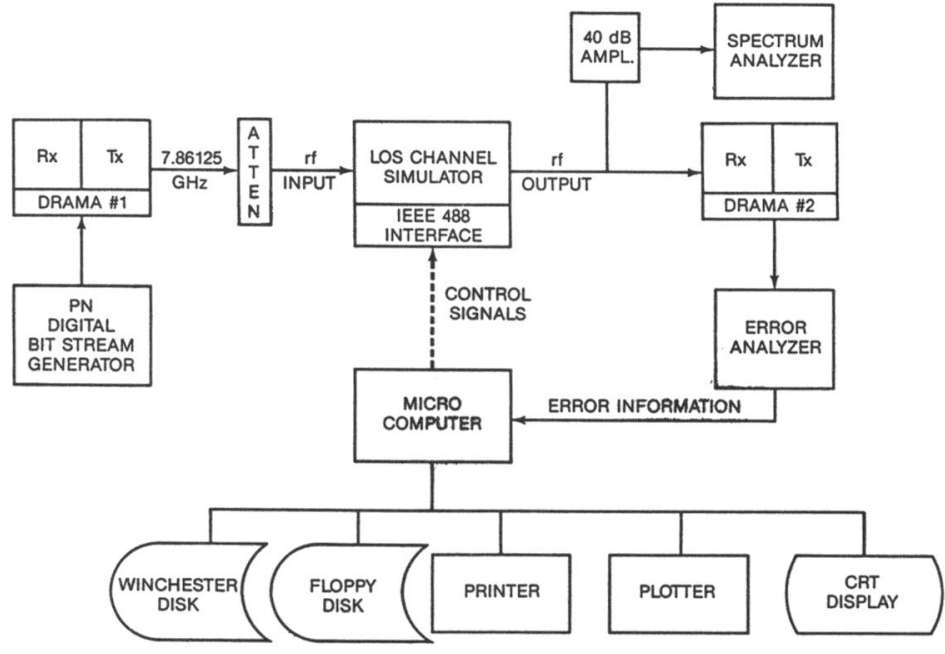

Figure 3. Radio test configuration. 


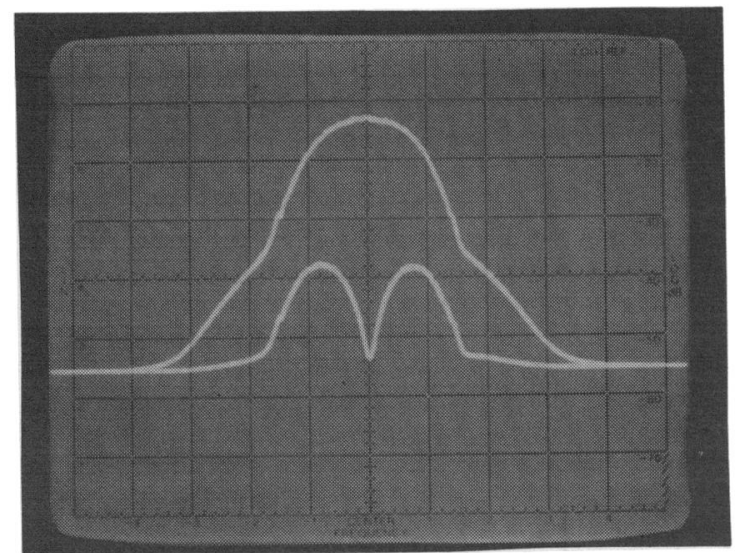

Figure 4. Simulator output; $\tau=6 \mathrm{~ns}, \mathrm{~B}^{\prime}=0$, $\mathrm{A}=-10 \mathrm{~dB}, \phi=2.8^{\circ}$ in top trace, $\phi=182.8^{\circ}$ in bottom trace; $5 \mathrm{MHz} / \mathrm{div}$, $10 \mathrm{~dB} / \mathrm{div}$, $0 \mathrm{dBm}$ reference level. Center frequency is $7.86125 \mathrm{GHz}$.

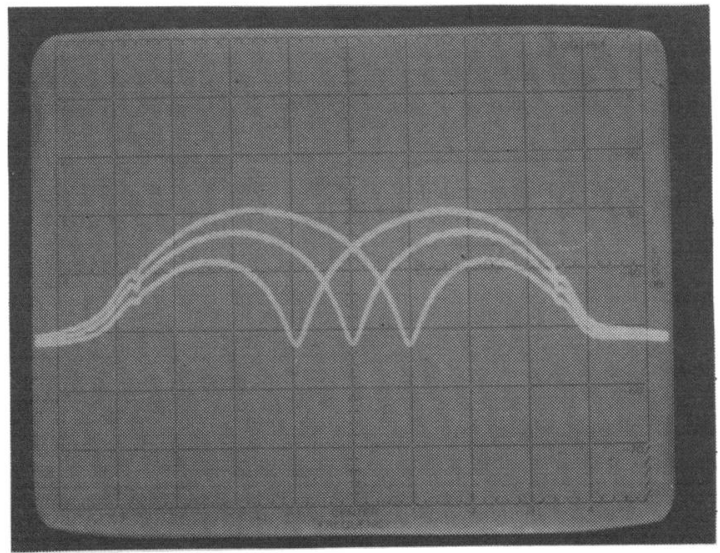

Figure 5. Simulator output; $\tau=10 \mathrm{~ns}, \mathrm{~B}^{\prime}=0$, $A=-10 \mathrm{~dB}$; three values of $\phi$ are $338.9^{\circ}, 345.9^{\circ}$, and $353.0^{\circ}$, which correspond to traces having notches on the left, center, and right, respectively; $2 \mathrm{MHz} / \mathrm{div} ., 10 \mathrm{~dB} / \mathrm{div}, \mathrm{dBm}$ reference level. Center frequency is $7.86125 \mathrm{GHz}$.

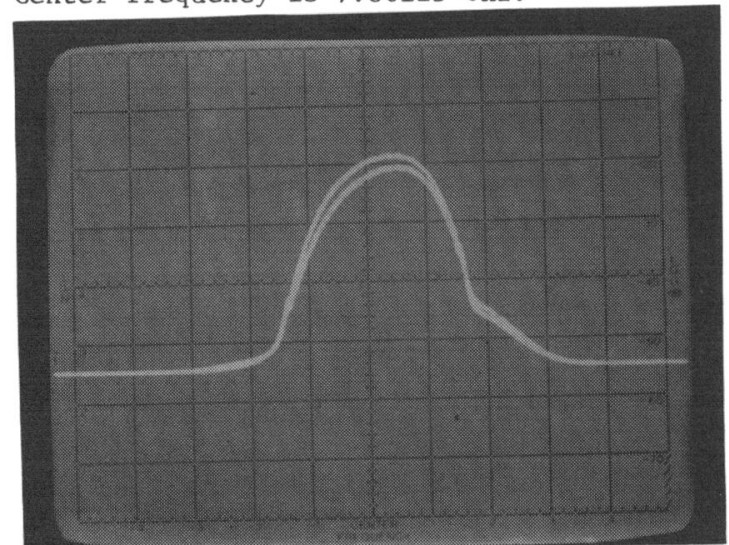

Figure 6. Simulator output; $\tau=12 \mathrm{~ns}, \mathrm{~B}^{\prime}=3.0 \mathrm{~dB}$, $A=-10 \mathrm{~dB} ; \phi=255.9^{\circ}$ in upper trace and $267.2^{\circ}$ in lower trace; $5 \mathrm{MHz} / \mathrm{div} ., 10 \mathrm{~dB} / \mathrm{div} ., 0 \mathrm{dBm}$ reference level. Center frequency is $7.86125 \mathrm{GHz}$.

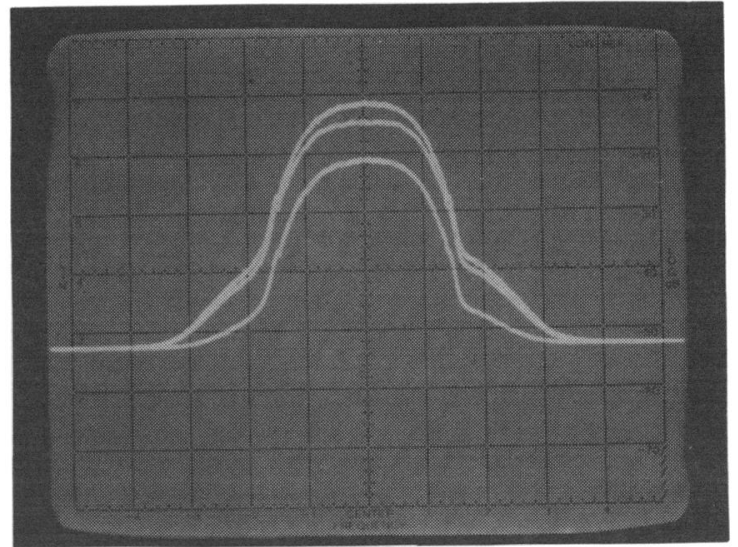

Figure 7. Simulator output; $\tau=12 \mathrm{~ns}, \phi=289.7^{\circ}$; top trace: $A=-10 \mathrm{~dB}, \mathrm{~B}^{\prime}=-5.0 \mathrm{~dB}$; center trace: $\mathrm{A}=-10 \mathrm{~dB}, \mathrm{~B}^{\prime}=-3.8 \mathrm{~dB}$; bottom trace: $\mathrm{A}=-20 \mathrm{~dB}$, $B^{\prime}=-5.0 \mathrm{~dB} ; 5 \mathrm{MHz} / \mathrm{div} ., 10 \mathrm{~dB} / \mathrm{div} .,-10 \mathrm{dBm}$ reference level. Center frequency is $7.86125 \mathrm{GHz}$.

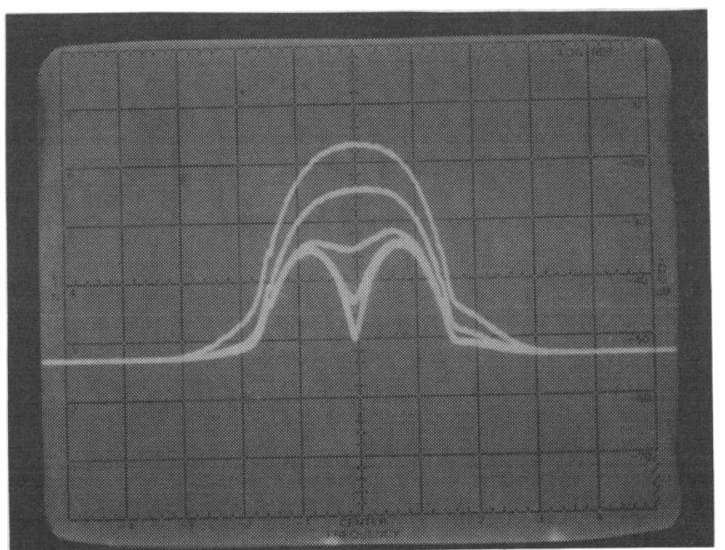

Figure 8. Simulator output; $\tau=3 \mathrm{~ns}, \phi=323.4^{\circ}$, $A=-10 \mathrm{~dB} ; B^{\prime}=-3.0,-1.4,-0.5,-0.2$, or 0.0 for the five traces (top to bottom, respectively); $5 \mathrm{MHz} /$ div., $10 \mathrm{~dB} / \mathrm{div} .,-10 \mathrm{dBm}$ reference level. Center frequency is $7.86125 \mathrm{GHz}$.

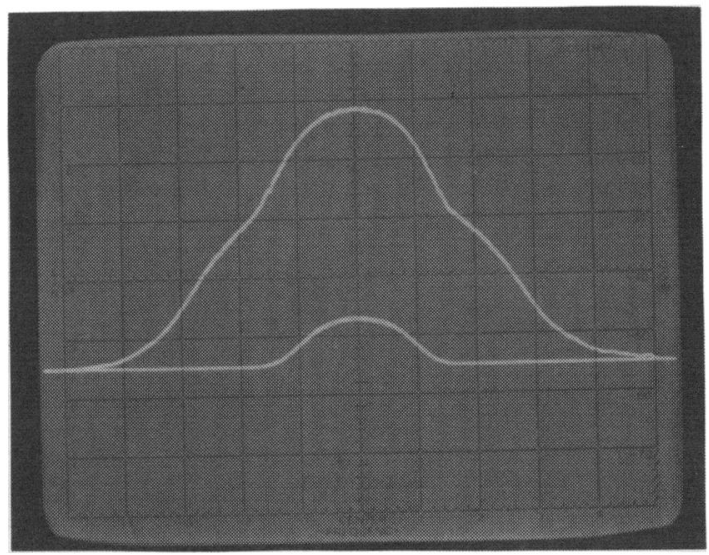

Figure 9. Simulator output; $\tau=12 \mathrm{~ns}, \phi=109.7^{\circ}$, $\mathrm{B}^{\prime}=-8.0 \mathrm{~dB}$; upper trace: $\mathrm{A}=-10 \mathrm{~dB}$; lower trace: $A=-52 \mathrm{~dB}, 5 \mathrm{MHz} / \mathrm{div}, 10 \mathrm{~dB} / \mathrm{div} ., 0 \mathrm{dBm}$ reference level. Center frequency is $7.86125 \mathrm{GHz}$. 


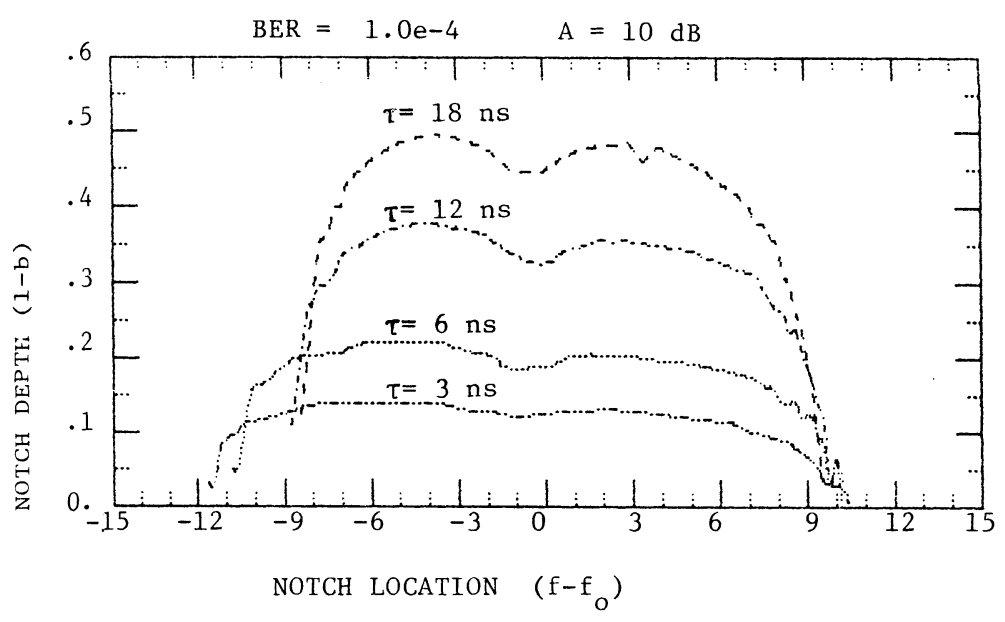

Figure 10. m-curve for $B^{\prime}<0$ (minimum phase).

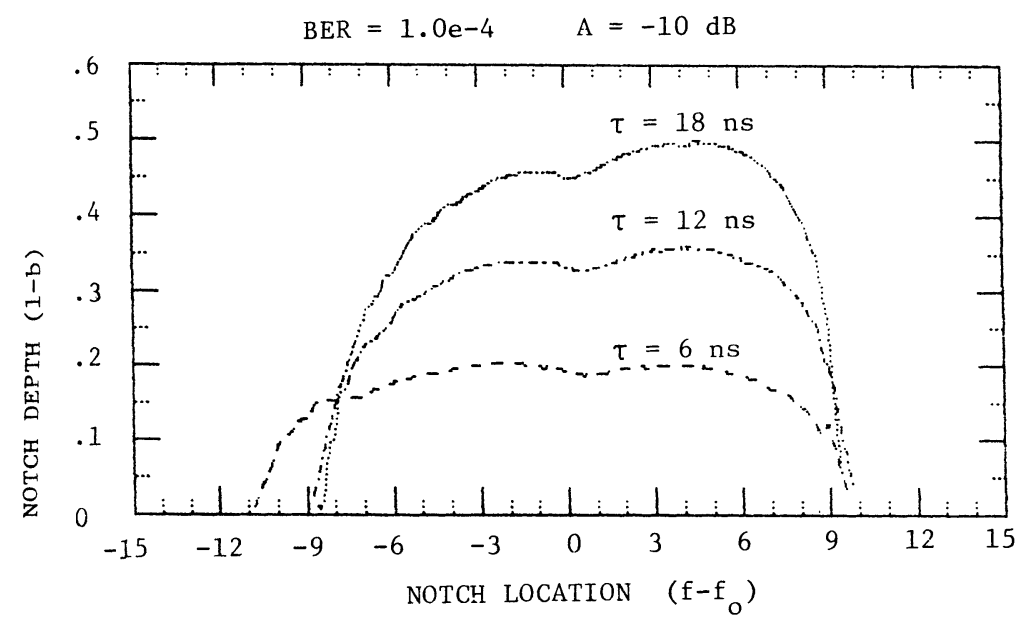

Figure 11. m-curve for $\mathrm{B}^{\prime}>0$ (nonminimum phase). 